\section{Indicadores das ações municipais para a notificação e o registro de casos de violência intrafamiliar e exploração sexual de crianças e adolescentes}

\author{
Indicators of local actions for reporting and \\ recording cases of domestic violence and sexual \\ exploitation of children and adolescents
}

Suely Deslandes 1

Corina Helena Figueira Mendes 1

Jeanne de Souza Lima 2

Daniel de Souza Campos 1
1 Instituto Fernandes Figueira, Fundação Oswaldo Cruz, Rio de Janeiro, Brasil. 2 Secretaria Municipal de Saúde e Defesa Civil, Rio de Janeiro, Brasil.

Correspondência S. Deslandes

Departamento de Ensino, Instituto Fernandes Figueira Fundação Oswaldo Cruz. Av. Rui Barbosa 716, Rio de Janeiro, RJ 22250-020, Brasil. desland@iff.fiocruz.br

\begin{abstract}
Information is essential for combating violence against children and adolescents and reclaiming their rights. This study presents indicators for the evaluation of local government actions for reporting and recording cases of domestic violence and sexual exploitation of children and adolescents, based on participatory, consensusbased methodologies: the nominal group technique (NGT) and the Delphi method. The frame of reference was the set of Brazilian policies focusing on the issue of violence against children and adolescence. Experts from Brazil's five major regions participated in the study. The consensus produced two different analytical scenarios, with three and 20 indicators, respectively.
\end{abstract}

Domestic Violence; Mandatory Reporting; Violence; Indicators

\section{Introdução}

A violência contra crianças e adolescentes é um relevante problema de saúde devido às consequências para o seu crescimento e desenvolvimento pleno 1. O Estatuto da Criança e do Adolescente (ECA) instituiu um novo paradigma de proteção integral, reconhecendo crianças e adolescentes como sujeitos de direitos. Nesta perspectiva, a população brasileira infanto-juvenil passa a ser prioritária no campo da formulação de políticas públicas e definição de recursos das instâncias político-administrativas do país. Com o promulgação do ECA, prevenir a ameaça ou violação de direitos contra crianças e adolescentes se tornou um dever de cada um e de toda a sociedade 2 .

Dentre as formas severas de violência contra crianças e adolescentes estão a violência intrafamiliar e a exploração sexual. A violência intrafamiliar pode se materializar sob a forma de abusos físicos, psicológicos, sexuais e pela negligência. Consiste em dinâmicas familiares pautadas no uso da violência para a solução de conflitos, como estratégia educacional, ou como expressão de afetos ${ }^{3}$. A exploração sexual de crianças e adolescentes é um fenômeno mundial que se caracteriza por uma relação de mercantilização do corpo com propósitos e usos sexuais e pode se apresentar sob a forma de prostituição, turismo sexual, pornografia e tráfico para fins sexuais 4,5 . 
O ECA prevê em seu Art. 13 que casos suspeitos ou confirmados de maus tratos contra crianças e adolescentes devem ser comunicados ao Conselho Tutelar, sem detrimento de outras medidas protetoras e legais. Além disso, tem definido no Art. 245 que médico e professor e os responsáveis das instituições de saúde e de ensino são obrigados a realizar esta comunicação e sujeitos a penalidades se não o fizerem 6 .

Em 2001, o Ministério da Saúde, reconhecendo que a violência contra crianças e adolescentes constitui um problema prioritário da agenda de Saúde Pública, institucionalizou a comunicação prevista no ECA através da notificação compulsória de casos suspeitos ou confirmados de maus tratos contra crianças e adolescentes atendidos no Sistema Único de Saúde (SUS) ${ }^{7}$. Esta decisão apoia-se também na Política Nacional de Redução de Morbimortalidade por Acidentes e Violências, em sua diretriz sobre o monitoramento das violências 8 .

Para o setor Saúde, a notificação compulsória consiste na comunicação obrigatória à autoridade sanitária da ocorrência de determinada doença ou agravo à saúde ou surto que deve ser feita por profissional de saúde ou qualquer cidadão, visando a adoção das medidas de intervenção pertinentes 9. Utilizando notificação compulsória como instrumento para a comunicação dos casos de violência contra crianças e adolescentes, o Ministério da Saúde passou a atuar de forma sistêmica na própria rede de proteção, já que uma cópia do documento deve ser encaminhada ao Conselho Tutelar da área de moradia da criança ou adolescente para que se criem meios para o monitoramento da situação.

Nesta perspectiva, o Ministério da Saúde vem desenvolvendo e aperfeiçoando sistemas nacionais de informações que permitam o monitoramento das causas externas (acidentes e violências) para fins de vigilância em saúde.

Em 2006, iniciou-se a implantação do Sistema de Vigilância de Violências e Acidentes (VIVA), com a finalidade de obter dados e divulgar as informações sobre violências e acidentes em quaisquer níveis de atendimento, permitindo conhecer a magnitude desses agravos. OVIVA foi estruturado em dois componentes: (i) vigilância contínua de violência doméstica, sexual e/outras violências interpessoais e autoprovocadas em hospitais de referências (VIVA contínuo) e; (ii) vigilância sentinela de violências e acidentes em emergências hospitalares (VIVA sentinela). A partir de 2009, a notificação de acidentes e violências passa a integrar o Sistema de Informação de Agravos de Notificações (Sinan Net) o que permitirá maior acessibilidade e análise das informações 10 .
Vale lembrar que o termo "notificação" é reconhecido pelo setor Saúde, todavia, em outros Setores a expressão utilizada é o de "comunicação" de violências. Neste artigo, adotaremos a expressão "notificação" para ambas as designações.

Nota-se que o setor Saúde, ainda que de forma lenta, progrediu no aperfeiçoamento de sistemas de informações voltados para as situações de violência, no entanto, os demais setores públicos, exceto a Segurança Pública e o Judiciário, ainda não apresentaram iniciativas abrangentes e sistematizadas sobre essa problemática.

A notificação é, portanto, um instrumento importante para dimensionar a magnitude dos casos de violência, e, consequentemente, permite estimar a necessidade de investimentos em núcleos de vigilância em saúde e serviços de assistência, assim como o desenvolvimento e aperfeiçoamento de redes de proteção. Considerando o ECA e o papel dos profissionais de saúde nestas redes, a notificação deve, sobretudo, acionar o Sistema de Garantia de Direitos, visando proteção infanto-juvenil e a interrupção das formas de abuso. Contudo, a prática de notificação ainda está desigualmente implantada no país. Pouco se conhece sobre as iniciativas regionais voltadas para o processo de notificação e qualificação do registro dos casos de violência contra crianças e adolescentes em suas diferentes formas, e, especialmente sobre as situações de exploração sexual.

O presente estudo é parte de uma pesquisa realizada em parceria com o Fundo das Nações Unidas para a Infância (UNICEF) que produziu um acervo de indicadores para a avaliação da atuação dos municípios dos centros urbanos brasileiros para o enfretamento da exploração sexual e da violência intrafamiliar contra crianças e adolescentes. O trabalho foi estruturado em cinco eixos temáticos: (i) prevenção da violência intrafamiliar e exploração sexual e promoção de relações familiares e comunitárias protetoras; (ii) atenção às vítimas destas violências e aos seus familiares; (iii) garantia dos direitos das crianças e adolescentes que sofrem estas violências; (iv) qualificação de registros e notificação de violência intrafamiliar e exploração sexual contra criança e adolescente; (v) responsabilização legal dos autores.

Este artigo apresenta o processo de construção e o conjunto de indicadores produzidos no que concerne à atuação governamental municipal para a notificação e a qualificação do registro. Tais indicadores oferecem subsídios para analisar, avaliar e monitorar o engajamento e a efetiva atuação dos governos locais no processo de comunicação da violência intrafamiliar e exploração sexual de crianças e adolescentes e nas 
formas de tratamento e qualificação destes registros, possibilitando a elaboração de diagnósticos que subsidiem o planejamento e investimento para a superação de lacunas e deficiências.

\section{Metodologia}

Trata-se de um estudo ancorado na triangulação de métodos participativos 11 voltados para a produção de consenso em torno de uma proposição de indicadores.

O marco teórico avaliativo foi construído a partir do estudo detalhado das principais políticas públicas e normas técnicas nacionais que abordam o enfrentamento da violência no país $6,7,8,12,13,14$

Estes documentos foram selecionados tendo como critérios: atualidade e vigência das referidas políticas; abrangência e validade para todo o território nacional e; diversidade de autorias e procedências segundo setores governamentais.

Elaborou-se a partir do estudo um plano avaliativo 15 , tomando-se a seguinte questão investigativa: os municípios têm consolidado a prática de notificação e o tratamento analítico destes registros? Os critérios de julgamento propostos foram: a oferta contínua de capacitação para a realização da notificação; o tratamento dado a estes registros; a qualidade do registro e, a existência de bancos e sistemas de informação.

Os indicadores iniciais foram criados pela equipe de pesquisa a partir das referidas políticas públicas que compunham o marco teórico avaliativo no que concerne ao registro e à notificação. A seguir, esses indicadores foram submetidos à crítica e ao exame de validação de representantes dos setores públicos e da sociedade civil, que também contribuíram com a criação de novos indicadores. Nesta fase foi aplicada a Técnica Grupo Nominal (TGN) que se caracteriza pela presença de sujeitos (especialistas) num encontro, onde os participantes relatam por escrito suas opiniões e propostas, discutidas junto ao grupo. A dinâmica se efetiva através da ação de um mediador, que propõe o debate entre os especialistas a partir de uma reunião estruturada, geralmente envolvendo entre 9 e 12 participantes 16,17 .

Neste estudo trabalhamos com o conceito de especialista numa perspectiva ampliada, incluindo desde a expertise acadêmica até profissionais cujas vivências eram significativas para a questão em foco 18 . Os especialistas participantes das diferentes etapas deste trabalho eram oriundos das áreas de Saúde, Assistência Social, Educação, Conselhos Tutelares e de Direitos, Varas da Infância e Juventude, Ministério Público
Estadual, Defensoria Pública, Turismo, Segurança Pública, Universidades e organizações da sociedade civil.

As sessões de TGN que discutiram registro e notificação envolveram 13 especialistas, distribuídos em dois encontros com duração de seis horas cada, realizados entre agosto e setembro de 2007.

Cada indicador formulado pela equipe de pesquisa, assim como os criados pelos participantes do TGN foi debatido e julgado pelos especialistas sobre sua importância através de um ranking ordinal (0 - sem importância alguma; 1 - quase sem importância; 2 - pouco importante; 3 - média importância; 4 -importante; 5 - muito importante; 6 -importantíssimo). Ao final, foram mantidos apenas os indicadores que obtiveram notas entre 5 e 6 por pelo menos $70 \%$ dos especialistas 18 .

Os encontros TGN foram gravados e transcritos, tendo sido analisados os conteúdos manifestos dos argumentos enunciados 19 . A seguir, foi construída uma matriz comparativa entre os indicadores produzidos pela equipe de pesquisa e pelos especialistas, verificando-se se havia repetições ou propostas que pudessem ser agrupadas. Ao final, a redação de todos os indicadores foi revista e padronizada.

A etapa subsequente foi a de seleção de especialistas em todas as regiões brasileiras e a submissão a eles do acervo de indicadores utilizando-se o Método Delphi. Este método foi desenvolvido na década de 1950 nos Estados Unidos, sendo definido como uma consulta estruturada a especialistas, buscando a convergência de análise sobre cenários futuros 20 . Tem sido aplicado a diversos campos do conhecimento, especialmente a área da saúde e demais políticas públicas 21. Apesar de suas variações, o Método Delphi possui algumas etapas que lhe são características 16: (i) os especialistas opinam sobre o problema em questão a partir de uma consulta prévia; (ii) cada um recebe um questionário com as propostas e problematizações para que responda demarcando a sua concordância ou discordância. Pode ser ainda solicitado a pontuar um escore ou hierarquia da importância daquele item no conjunto analisado; (iii) as respostas são tabuladas e podem ser novamente submetidas a cada sujeito do grupo.

Em nosso estudo, a consulta prévia foi construída a partir da TGN. Iniciamos a utilização do Método Delphi com a aplicação de questionário por via eletrônica (e-mail) e, posteriormente submetemos uma nova versão do questionário somente com os indicadores que não obtiveram consenso na primeira consulta.

A seleção do grupo de especialistas para o Delphi contou com o apoio dos escritórios regio- 
nais do UNICEF que encaminharam listas de sugestões de profissionais de diversas áreas que trabalhavam no sistema de garantia dos direitos de crianças e adolescentes ou com o atendimento às vítimas de violências. Todos estes especialistas indicados foram consultados, tendo sido solicitado a eles novas indicações (técnica snow ball). Além destes, compuseram o grupo os coordenadores dos Núcleos de Prevenção da Violência e de Acidentes à época; alunos e tutores do curso de educação à distância (EAD) Impactos da Violência na Saúde, oferecido pela Fundação Oswaldo Cruz; especialistas selecionados a partir de consulta sobre autores de artigos científicos sobre o tema, constantes na base SciELO e também aos diretórios dos grupos de pesquisa na Plataforma Lattes do Conselho Nacional de Desenvolvimento Científico e Tecnológico (CNPq).

Foi então enviado a cada especialista, via email, um instrumento contendo um guia de preenchimento e o rol dos indicadores aprovados no TGN. A fim de se verificar a consistência dos indicadores, foi solicitado aos especialistas que atribuíssem a mesma escala de 0 a 6 utilizada no TGN a cada indicador para cada um dos seguintes critérios: (i) clareza da redação; (ii) relevância e, (iii) facilidade de acesso aos dados.

Ao todo foram convidados 746 especialistas oriundos das cinco regiões, compondo uma amostra de conveniência e 164 (22\%) responderam à primeira consulta da etapa Delphi.

No que concerne à adesão de participação, vale destacar as dificuldades apontadas na literatura sobre as consultas por meio da Internet. Os estudos com o Delphi apontam como problema usual a baixa adesão 22,23. Um segundo aspecto diz respeito à extensão da consulta. Geralmente, estudos que se utilizam deste método operam com amostras bem mais modestas. Considerando as escolhas metodológicas, ou a raridade da área, há estudos que trabalham com 10 especialistas ou menos 24 . Autores defendem que 15 a 30 especialistas constituem número suficiente para o uso do método 20.

Tomando-se a inserção regional dos especialistas a quem foi enviado o instrumento e os que responderam, verificou-se a seguinte distribuição entre convidados e respondentes por regiões: Centro-oeste (76 e 12), Nordeste (196 e 40), Norte (90 e 16), Sudeste (286 e 79), Sul (98 e 17). Como se verifica, houve um predomínio da Região Sudeste, seja entre os convidados, seja entre os que responderam. Tal fato se explica pela notória concentração de especialistas nesta região. A Região Nordeste despontou como lócus de especialistas na temática. Vale pontuar que no grupo dos respondentes da primeira consulta do Delphi há representantes de 25 estados e Distrito Federal.

\section{Análise do Delphi}

Usamos a mediana $\left(M_{d}\right)$, que pode ser considerada uma boa aproximação do grau de representatividade de cada um dos critérios, complementada pelo intervalo interquartil $\left(d_{q}\right)$, dado que consiste numa medida que se aproxima do grau de consenso 25. Buscamos saber que notas foram atribuídas aos indicadores, além de analisar o grau de consenso observado nestas opiniões.

Definimos então que os indicadores que obtiveram nas três variáveis (clareza, relevância e facilidade de acesso) um alto valor de representatividade, entre 4 e 6, e um alto grau de consenso em todos os critérios, seriam imediatamente aprovados e não passariam por um novo crivo dos especialistas. Também receberia aprovação na primeira consulta Delphi o indicador que, mesmo não tendo alcançado consenso nas três variáveis, estivesse variando em torno dos valores de 4 a 6 . Estes também não seriam reapresentados porque a falta de consenso oscilara entre padrões muito positivos.

Os indicadores que obtiveram em qualquer variável um valor de $M_{d}=3$ (escore de aprovação regular) e um alto grau de consenso, ou os que obtiveram um valor de $M_{d}<3$ (escore de aprovação baixo), independente de ter alcançado consenso, seriam descartados.

Para qualquer outro cenário o indicador seria novamente apresentado aos especialistas.

Os indicadores que não obtiveram consenso foram novamente submetidos ao escrutínio dos 164 especialistas que aderiram ao estudo. De todo o acervo de indicadores apenas o item "facilidade de acesso" não obteve consenso, assim somente este quesito foi novamente submetido à consulta. Na segunda rodada, 120 especialistas responderam $(73,17 \%)$. Nosso percentual de adesão corrobora os achados de Wright \& Giovinazzo 22 que consideram esperada uma abstinência de 20 a $30 \%$ na segunda rodada.

Como é preconizado pelo método Delphi 22,26, o especialista recebeu a informação sobre sua resposta anterior e a resposta do grupo consolidada, sendo perguntado se ele desejaria alterar ou manter sua resposta.

Dada a heterogeneidade dos especialistas, consideramos oportuno interrogar sobre seu efetivo grau de certeza (opções entre 0 a 100\%) sobre o que opinavam: o acesso aos dados relacionados a cada indicador. Com esta medida, buscamos minimizar o impacto das respostas sobre a variável (acesso ao dado) que estivessem claramente baseadas no senso comum. Nesta segunda consulta, só foram calculadas aquelas respostas cujo grau de certeza fosse igual ou superior a $60 \%$, assim houve variação no $\mathrm{N}$ de cada resposta. 
Nesta segunda etapa de análise, observamos os mesmos critérios de exclusão e de consenso adotados na primeira fase. Como opção mais flexível ao conjunto de indicadores oriundos desta análise (mediana $\geq 4$ ), criamos um segundo cenário de indicadores, mais flexível, a partir de um ponto de corte menor (mediana $\geq 3$ e intervalos interquartis $>1$ ), aceitando os indicadores com "média facilidade de acesso aos dados", abrangendo um maior número de indicadores.

A aplicação do Delphi foi realizada em três meses, sendo finalizado o estudo em 2008. A pesquisa foi financiada pelo UNICEF e CNPq e foi submetida e aprovada por Comitê de Ética em Pesquisa vinculado à Comissão Nacional de Ética em Pesquisa (CONEP).

\section{Resultados}

Indicadores construídos pela equipe de pesquisa e julgados pelos especialistas na etapa TGN

A equipe de pesquisa elaborou 19 indicadores relacionados à temática notificação e registro que foram submetidos aos especialistas na etapa TGN do estudo (Tabela 1).

Um aspecto fundamental dentre os indicadores escolhidos refere-se à prática sistemática de notificação de violência intrafamiliar que deve ser realizada aos Conselhos Tutelares. Esta prática é legalmente estabelecida no ECA e ratificada em todas as políticas posteriores, constituindose um marco elementar da atuação dos setores de Saúde, Educação e Assistência Social no enfrentamento da violência contra crianças e adolescentes. Considerando-se esta base fundamental, foram criados os indicadores de 1 a 7 .

Os indicadores seguintes, 8 e 9, analisam a questão da capacitação para a notificação. Uma vez que esta prática ainda não foi definitivamente incorporada na cultura da atenção e cuidado às crianças e aos adolescentes por diversos setores, a capacitação de profissionais se torna ação estratégica.

Esta demanda é amplamente reconhecida pelas principais políticas públicas de diversos setores para o enfrentamento da violência no país e incorporada pela Política Nacional de Redução de Morbimortalidade por Acidentes e Violências 8 (p. 28) que postula como uma de suas diretrizes: "Capacitação e a mobilização dos profissionais de saúde que atuam em todos os níveis de atendimento do SUS, inclusive nas unidades de urgência e emergência, com vistas a superar os problemas relacionados à investigação e à informação relativa a acidentes e violências".
A consolidação do processo de notificação de violência contra crianças e adolescentes demanda a gestão das informações geradas, o que inclui desde a elaboração e integração de bancos de dados, a análise dos registros, investimento contínuo da qualidade dos dados, até a divulgação destes dados à sociedade e aos gestores que atuam no planejamento de ações de prevenção e de atenção às vítimas e seus familiares.

Neste sentido, a Política Nacional de Redução de Morbimortalidade por Acidentes e Violência 8 (p. 29) preconiza como uma de suas diretrizes a: "Promoção do registro contínuo padronizado e adequado das informações, de modo a possibilitar estudos e elaboração de estratégias de intervenção acerca dos acidentes e das violências relacionados aos diferentes segmentos populacionais, segundo a natureza e o tipo de lesões e de causas, a partir dos quais se viabilizará a retroalimentação do sistema, contribuindo, assim, para a melhoria do atendimento prestado a estes segmentos".

As competências da gestão destas informações também estão definidas pelas demais políticas que compõem o marco referencial deste estudo. A Política Nacional de Enfrentamento ao Tráfico de Pessoas 14 destaca a responsabilidade dos órgãos e entidades públicas a fim de organizar e integrar os bancos de dados existentes na área de enfrentamento ao tráfico de pessoas (Art. 8o)

Com base nestas orientações foram criados os indicadores de 10 a 13. Os indicadores 17 e 18, por sua vez, complementam os anteriores, abordando a questão da articulação entre os sistemas de informações.

Outro importante aspecto é o fluxo e tratamento destas informações, que são contemplados pelos indicadores de 14 a 16. Os Parâmetros para Criação e Funcionamento dos Conselhos Tutelares 12 (p. 26), por seu turno, orientaram sobre o caminho a ser percorrido: Art. 3o, § 1o "Os Conselhos Tutelares deverão produzir estatísticas mensais de seu atendimento a serem encaminhadas às Coordenadorias Regionais de Assistência Social, ao Conselho Municipal dos Direitos da Criança e do Adolescente e, posteriormente, ao Ministério Público e ao Juizado da Infância, da Juventude e do Idoso de forma a subsidiar a elaboração da política de atendimento à população infanto-juvenil".

Outra questão crucial é a qualificação do registro. A condição étnica hoje é reconhecida como informação importante, dadas as evidências de maior vulnerabilidade em diferentes situações, como a do tráfico de pessoas e de exploração sexual. A Política Nacional de Enfrentamento ao Tráfico de Pessoas recomenda em seu oitavo artigo a realização de estudos e pesquisas sobre o 
Tabela 1

Indicadores propostos pela equipe de pesquisa.

Indicadores propostos pela equipe

1. Número de notificações/comunicações de violência intrafamiliar contra crianças e adolescentes realizadas aos Conselhos Tutelares do município

2. Número de notificações/comunicações de exploração sexual contra crianças e adolescentes realizadas aos Conselhos Tutelares do município

3. Percentual de notificações/comunicações de violência intrafamiliar contra crianças e adolescentes realizadas por profissionais de saúde aos Conselhos Tutelares do município

4. Número de notificações/comunicações de exploração sexual de crianças e adolescentes realizadas por profissionais de saúde aos Conselhos Tutelares do município

5. Percentual de notificações/comunicações de violência intrafamiliar contra crianças e adolescentes realizadas por profissionais de educação aos Conselhos Tutelares do município

6. Número de notificações/comunicações de exploração sexual contra crianças e adolescentes realizadas por profissionais de educação aos Conselhos Tutelares do município

7. Número de notificações de exploração sexual realizadas pelo setor saúde ao Conselho Tutelar

8. Percentual de profissionais de saúde da rede pública municipal sensibilizados/capacitados para notificação de violência intrafamiliar contra crianças e adolescentes

9. Percentual de profissionais de emergência-urgência sensibilizados/capacitados para notificação de violência intrafamiliar contra crianças e adolescentes

10. Percentual de notificações de violência intrafamiliar em que a variável cor é preenchida

11. Percentual de notificações de exploração sexual contra criança e adolescente em que a variável cor é preenchida

12. Existência de banco de dados intersetorial de violência intrafamiliar contra crianças e adolescentes atualizado e disponível para consulta de gestores de setores públicos

13. Existência de rotinas de disseminação da informação sobre as notificações às unidades que realizam atenção às crianças e adolescentes

14. Percentual de Conselhos Tutelares que produzem estatísticas mensais de seu atendimento

15. Percentual de Conselhos Tutelares que estão cadastrados no Sistema de Informação para a Infância e Adolescência (SIPIA) e alimentam regularmente esta base de dados

16. Percentual de Conselhos Tutelares que enviam estatísticas mensais de atendimento às Coordenadorias Regionais de Assistência Social (CRAS) e Conselho Municipal de Direitos da Criança e Adolescente (CMDCA)

17. Existência de cadastro atualizado das instituições governamentais e não governamentais e de programas que prestam assistência a crianças e adolescentes vítimas de exploração sexual divulgadas ao público

18. Existência de sistema articulado e informatizado de notificações de violência sexual contra crianças e adolescentes entre Conselhos Tutelares, Delegacias, Delegacias Especializadas (Criança e Mulher), Disques-Denúncia nacional, estadual e municipal

19. Número de serviços para denúncia de exploração sexual atuantes no município

perfil das vítimas de tráfico de pessoas com ênfase na população negra e outros segmentos étnicos da população brasileira 14 . Os indicadores 10 e 11 buscam atender tal direção.

Finalmente, o indicador 19 enfatiza a importância da existência e efetividade de serviços de denúncias e de registro de situações de exploração sexual atuantes no município.

Os indicadores 2, 4, 6 e 7 foram inicialmente rejeitados pelos especialistas participantes da etapa TGN do estudo que consideraram que o número absoluto não seria uma boa medida de abordagem. No entanto, reconhecendo-se a invisibilidade construída em torno do problema da exploração sexual, apesar de suas limitações, o "número de denúncias" foi considerado capaz de configurar como uma medida de aproximação do fenômeno.
O indicador 9 foi questionado quanto a sua pouca clareza: “...não define o que vai ser comunicado como "sensibilizado/capacitado" Esta dúvida pode levar a dificuldade no preenchimento do indicador" (Especialista TGN).

Já o indicador 19 foi considerado inadequado por sugerir como desejável a existência de vários serviços.

"É melhor um serviço concentrador de denúncia do que vários serviços" (Especialista TGN).

Os demais indicadores foram aprovados pelos especialistas.

\section{Indicadores construídos pelos especialistas na etapa TGN}

No inicio do encontro TGN, sem conhecimento prévio dos indicadores criados pela equipe de 
pesquisa, os especialistas formularam 25 indicadores e aprovaram 18 (Tabela 2). Percebe-se que há semelhança entre indicadores apresentados pelos especialistas com os que a equipe havia formulado.

Em síntese, os indicadores criados pelos especialistas no TGN expressaram suas preocupações com a sistematização, qualidade e atualidade do registro.

A qualidade do registro enfocou não somente a capacidade de preenchimento das variáveis constantes nas fichas de notificação, mas também a questão da variável cor, como elemento diferenciador deste nível de qualidade, corroborando as orientações da Política Nacional de Enfrentamento ao Tráfico de Pessoas 14.

Outro aspecto oportunamente sugerido pelos especialistas foi enfatizar a visibilidade da situação da exploração sexual nos registros, geralmente subnotificada ou incluídos sob outros campos, problema que tem sido exaustivamente denunciado nos congressos internacionais e reconhecido pelas autoridades públicas 27 .

A questão da capacitação abordou a formação de profissionais tanto para a notificação quanto para o tratamento e a análise do registro, seja no âmbito das secretarias municipais, seja no dos Conselhos Tutelares. Em consonância a diferentes políticas setoriais sobre o tema $3,8,14$, os especialistas também detalharam a necessidade da disponibilidade de profissionais capacitados para a notificação em todo o município ("Percentual de profissionais de saúde capacitados para registro das fichas de notificação compulsória de maus tratos contra crianças e adolescentes, segundo Região Administrativa"), ressaltando que seria necessário demarcar um recorte do tempo e periodicidade da oferta de tais atividades.

"Seria melhor medir o percentual de profissionais da área de saúde capacitados e isso tudo tem que ter também um período X". "E não por unidade”. “...porque também não adianta, ele pode ter capacitado 500 há 10 anos atrás e nunca mais capacitar ninguém" (Especialistas TGN).

A notificação foi abordada tendo como foco o seu instrumento de comunicação no setor saúde, a ficha de notificação, reconhecida como importante e estratégico meio de garantia de direitos, conforme a proposta do VIVA 10 . Mas também foi reconhecido que outros setores podem ter outras formas de padronização da comunicação das formas de violências às autoridades competentes: "Eu acho que ficha é da saúde, a notificação pode, porque assim o ECA não vai falar de ficha, fala de

Tabela 2

Indicadores propostos pelos especialistas no TGN

Indicadores propostos pelos especialistas

1. Existência de bancos de dados, atualizados no máximo semestralmente, referentes à violência intrafamiliar contra crianças e adolescentes

2. Existência de processo sistematizado de divulgação dos dados analisados referentes à violência intrafamiliar contra crianças e adolescentes

3. Existência da variável raça/cor nas fichas de notificações (segundo padrão do Instituto Brasileiro de Geografia e Estatística)

4. Percentual de fichas de notificação adequadamente preenchidas (em todos os seus campos) no município

5. Percentual de profissionais de saúde capacitados para registro das fichas de notificação compulsória de maus-tratos contra crianças e adolescentes, segundo região administrativa

6. Existência de normatização de fluxo para as fichas de notificação compulsória de maus-tratos contra crianças e adolescentes no município

7. Existência de instrumento padronizado de notificação de violência intrafamiliar contra crianças e adolescentes em cada secretaria municipal

8. Existência de equipe capacitada para digitação e análise dos dados existentes nas fichas de notificação compulsória de maus-tratos contra criança e adolescente

9. Existência de infraestrutura (recursos) para digitação e análise dos dados existentes nas fichas de notificação compulsória de maus-tratos contra criança e adolescente

10. Existência de equipe capacitada para digitação e análise das notificações nos Conselhos Tutelares

11. Existência de infraestrutura (recursos) para digitação e análise das notificações nos Conselhos Tutelares

12. Existência de capacitações que incluam o tema da identificação e registro das situações de violência contra a criança e adolescente

13. Existência de bancos de dados provenientes dos serviços telefônicos de atendimento e denúncias de violências contra crianças e adolescentes

14. Existência de estatísticas atualizadas (semestralmente) pelo setor saúde sobre exploração sexual

15. Número de ocorrências policiais de casos de exploração sexual de crianças e adolescentes

16. Existência da tipologia da exploração sexual no Sistema de Informação para a Infância e Adolescência (SIPIA)

17. Existência de estatísticas atualizadas pelo SIPIA sobre exploração sexual

18. Número de denúncias de exploração sexual realizadas através de sistema de denúncia telefônica contra crianças e adolescentes 
comunicação". "Pode ser que a educação defina esse instrumento com um outro nome". "Não podemos colocar instrumento padronizado? (Todos concordam)" (Especialistas TGN).

Os especialistas consideraram que a existência de fichas ou outros instrumentos padronizados para a notificação de violências contra crianças e adolescentes deve ser responsabilidade de todas as secretarias municipais e não somente das de Saúde e Educação.

Também foi abordada a importância de definição de um fluxo a ser seguido no encaminhamento dos instrumentos de notificação: "Porque a existência [do fluxo] está lá, agora cada um faz o que quer. Um manda direto pro conselho, outro manda pra secretaria de saúde, a outra manda pra lugar nenhum". "Pois é... o fluxo existe. Mas estamos pensando na realidade de outros municípios que podem ter ou não..." (Especialistas TGN).

Por fim, o debate apontou ainda a preocupação dos especialistas com a consolidação de um sistema de informação, denotando a responsabilidade do município na gestão da informação, investindo desde a sensibilização para a notificação e registro, até o tratamento dispensado aos dados, sua periodicidade e divulgação.

"É um sistema de gestão. Quando eu falo em gestão da informação e não simplesmente a ficha, eu estou falando tudo, desde a produção desse dado até a divulgação, a acessibilidade. (...). A qualidade na hora da coleta, a qualidade na hora de formação de consolidar até a divulgação. Isso é um sistema de gestão" (Especialista TGN).

Indicadores analisados por especialistas brasileiros: consulta pelo Método Delphi

Após análise comparativa entre os indicadores formulados pela equipe de pesquisa e pelos especialistas do TGN, foram realizadas correções na redação e consolidados os indicadores em uma nova versão.

A nova lista constou de 22 indicadores e foi encaminhada para análise de especialistas de todo país através do Método Delphi (Tabela 3).

Os indicadores foram agrupados em 4 blocos de descritores a partir das seguintes temáticas: (i) Efetiva capacidade de notificar e registrar casos de violência intrafamiliar e exploração sexual (descritores de 1 a 4); (ii) Investimento na capacitação de profissionais para notificação e registro (descritores 5 e 6); (iii) Investimento na construção de sistemas de notificação e registro (descritores de 7 a 9) e, (iv) Qualidade do registro (descritores 10 e 11).

A primeira etapa do Delphi produziu os seguintes resultados (Tabela 4): dois indicadores foram aprovados (2.1 e 2.2); um foi rejeitado (1.4) e 19 indicadores não obtiveram consenso e retornaram em novo instrumento a fim de serem submetidos à segunda consulta. A aprovação inicial dos dois indicadores provavelmente deve-se ao conhecimento prévio da existência de ficha de notificação dos atendimentos por violência e de disponibilidade de equipe para a análise de dados no setor Saúde, dada sua atuação histórica no setor de Vigilância.

Na segunda etapa do Delphi um indicador foi aprovado (4.1) e os outros 18, rejeitados. O motivo de rejeição dos indicadores foi por terem sido julgados como de difícil obtenção de dados, revelando pouca confiança acerca da disponibilidade da informação sobre violência nos setores públicos, opinião que encontra evidências em estudos sobre o tema 28,29 .

Contudo, como se vê (Tabela 5), adotando-se uma postura mais flexível, assumindo a $M_{d}=3$ (médio acesso aos dados), o cenário pode inverter-se por completo, pois 18 indicadores seriam selecionados e apenas um rejeitado, configurando um total de 20 indicadores (dois aprovados na primeira consulta e 18 aprovados na segunda consulta).

\section{Alguns pontos para o debate}

De acordo com Njaine et al. ${ }^{29}$, a informação sobre violência assume grande importância quando é reconhecida como um direito da sociedade e não como um produto de uso privado de instituições, sejam elas científicas, burocráticas, administrativas ou de comunicação.

Nesta perspectiva, a notificação é essencial ao enfrentamento das diversas formas de violência contra crianças e adolescentes e no processo de restauração de seus direitos. Além de possibilitar a interrupção do abuso e desencadear medidas de proteção e assistência a vítimas e familiares, também oferece informações para avaliação da situação local e da necessidade de investimentos públicos.

A criação de mecanismos avaliativos sobre este tema ainda constitui uma lacuna no campo das políticas públicas brasileiras. Neste sentido, as metodologias participativas mostramse adequadas para a produção de critérios ou indicadores de avaliação quando não existem parâmetros técnico-científicos reconhecidos e validados 15,16. A escolha destes caminhos na construção dos indicadores expressa um princípio ético de respeito a opiniões, expectativas, saberes e experiências daqueles que estudam o tema e trabalham no enfrentamento da violência intrafamiliar e da exploração sexual de crianças e 
Tabela 3

Indicadores apresentados à consulta de especialistas brasileiros para qualificação do registro e notificação de situações de violência intrafamiliar e de exploração sexual.

\section{Descritor}

1. Realização de notificações/comunicações de violência intrafamiliar e exploração sexual contra crianças e adolescentes aos Conselhos Tutelares

2. Investimento no sistema de registro/notificação de violências contra crianças e adolescentes no âmbito das secretarias municipais

3. Sistema de informação que organize e integre bancos de dados sobre exploração sexual de crianças e adolescentes

4. Existência de sistema de denúncias telefônicas de exploração sexual contra crianças e adolescentes

5. Profissionais de saúde de todos os níveis de atenção capacitados para realizar registro e notificação de violência intrafamiliar contra crianças e adolescentes

6. Capacitação dos profissionais da saúde, educação, assistência social, guarda municipal e Conselhos Tutelares para notificação/ comunicação e registro de situações de violência contra crianças e adolescentes

7. Investimento nos Conselhos Tutelares para a consolidação do Sistema de Informação para a Infância e Adolescência (SIPIA)

8. Produção de estatística pelo setor saúde sobre exploração sexual contra crianças e adolescentes

\section{Indicador}

1.1. Número de notificações/comunicações de violência intrafamiliar contra crianças e adolescentes realizadas aos Conselhos Tutelares

1.2. Percentual de notificações de violência intrafamiliar contra crianças e adolescentes realizadas por profissionais de saúde aos Conselhos Tutelares

1.3. Percentual de notificações de exploração sexual realizadas por profissionais de saúde aos Conselhos Tutelares

1.4. Percentual de notificações/comunicações de violência intrafamiliar contra crianças e adolescentes realizadas por profissionais de educação aos Conselhos Tutelares

2.1. Existência de instrumento padronizado de notificação/comunicação de violência intrafamiliar contra crianças e adolescentes nas secretarias municipais 2.2. Existência de equipe capacitada na Secretaria Municipal de Saúde para sistematização e análise dos dados existentes nas fichas de notificação compulsória de maus-tratos contra crianças e adolescentes

2.3. Existência de infraestrutura (recursos materiais) para sistematização e análise dos dados existentes nas fichas de notificação compulsória de maus-tratos contra crianças e adolescentes

2.4. Existência de normatização de fluxo para as fichas de notificação compulsória de maus-tratos contra crianças e adolescentes preenchidas pelos profissionais das unidades municipais de saúde

3.1. Existência de rotinas de retorno da informação sobre as notificações de violência intrafamiliar e exploração sexual às unidades que realizam atenção às crianças e adolescentes

3.2. Existência de sistema articulado e informatizado de informação sobre notificações/comunicações de exploração sexual realizadas entre Conselhos Tutelares, delegacias, delegacias especializadas, Disques-denúncia nacional, estadual e municipal

4.1. Número de denúncias de exploração sexual contra crianças e adolescentes realizadas através de sistema de denúncia telefônica

4.2. Existência de banco de dados provenientes dos serviços telefônicos de atendimento às denúncias de violências contra crianças e adolescentes

5.1. Percentual de profissionais de saúde capacitados para registro e notificação de casos suspeitos e/ou confirmados de violência intrafamiliar contra crianças e adolescentes, segundo região administrativa

6.1. Existência de capacitações nos setores da saúde, educação, assistência social, guarda municipal e Conselhos Tutelares que incluam a identificação, notificação e registro das situações de violência contra crianças e adolescentes

7.1. Existência de equipe capacitada nos Conselhos Tutelares para sistematização e análise das notificações/comunicações de violência contra criança e adolescente

7.2. Existência de infraestrutura (recursos) nos Conselhos Tutelares para sistematização e análise das notificações/comunicações de violência contra criança e adolescente

8.1. Existência de estatísticas atualizadas (semestralmente) pelo setor saúde sobre exploração sexual contra crianças e adolescentes

(continua) 
Tabela 3 (continuação)

Descritor Indicador

9. Produção de estatística por Conselhos Tutelares sobre atendimentos a situações de violência intrafamiliar e exploração sexual contra crianças e adolescentes

10. Valorização das questões étnico-raciais na informação sobre eventos de violências contra criança e adolescentes

11. Qualidade de preenchimento de fichas de notificação de maus-tratos contra crianças e adolescentes no âmbito dos serviços de saúde
9.1. Percentual de Conselhos Tutelares que produzem estatísticas mensais de seu atendimento a situações de violência intrafamiliar e exploração sexual contra crianças e adolescentes

9.2. Percentual de Conselhos Tutelares que estão cadastrados no SIPIA e alimentam regularmente esta base de dados

9.3. Percentual de Conselhos Tutelares que enviam estatísticas mensais de atendimento aos Centros de Referência de Assistência Social (CRAS) e ao Conselho Municipal de Direitos da Criança e Adolescente (CMDCA)

10.1. Existência da variável raça/cor nos instrumentos de notificação/comunicação de violência intrafamiliar e de exploração sexual adotados pelas secretarias municipais (segundo padrão Instituto Brasileiro de Geografia e Estatística) 11.1. Percentual de fichas de notificação de maus-tratos contra crianças e adolescentes adequadamente preenchidas pelos profissionais de saúde da rede municipal (preenchidas em todos os campos)

Tabela 4

Indicadores para qualificação do registro e notificação de situações de violência intrafamiliar e de exploração sexual segundo comportamento nas duas rodadas Delphi.

\begin{tabular}{|c|c|c|c|c|c|c|c|c|c|c|}
\hline \multirow{3}{*}{ Indicadores } & \multicolumn{6}{|c|}{ RODADA 1} & \multirow{3}{*}{ Status } & \multicolumn{3}{|c|}{ RODADA 2} \\
\hline & \multicolumn{2}{|c|}{ Facilidade } & \multicolumn{2}{|c|}{ Clareza } & \multicolumn{2}{|c|}{ Relevância } & & \multicolumn{2}{|c|}{ Facilidade } & \multirow[t]{2}{*}{ Status } \\
\hline & Mediana & DIQ & Mediana & DIQ & Mediana & DIO & & Mediana & DIQ & \\
\hline \multicolumn{11}{|l|}{ Eixo 4} \\
\hline 1.1. & 3 & 2 & 4 & 1 & 5 & 1 & Sem consenso & 3 & 1 & Rejeitado \\
\hline 1.2. & 3 & 2 & 4 & 1 & 5 & 1 & Sem consenso & 3 & 1 & Rejeitado \\
\hline 1.3. & 3 & 2 & 4 & 1 & 5 & 1 & Sem consenso & 3 & 1 & Rejeitado \\
\hline 1.4. & 3 & 1 & 4 & 1 & 5 & 1 & Rejeitado & - & - & - \\
\hline 2.1. & 4 & 1 & 4 & 0 & 5 & 1 & Aprovado & - & - & - \\
\hline 2.2 & 4 & 1 & 4 & 0 & 5 & 1 & Aprovado & - & - & - \\
\hline 2.3 & 3 & 2 & 4 & 1 & 5 & 1 & Sem consenso & 3 & 1 & Rejeitado \\
\hline 2.4 . & 3 & 2 & 4 & 1 & 5 & 1 & Sem consenso & 3 & 1 & Rejeitado \\
\hline 3.1. & 3 & 2 & 4 & 1 & 5 & 1 & Sem consenso & 3 & 1 & Rejeitado \\
\hline 3.2 . & 3 & 2 & 4 & 1 & 5 & 1 & Sem consenso & 3 & 1 & Rejeitado \\
\hline 4.1. & 3,5 & 2 & 4 & 0,5 & 5 & 1 & Sem consenso & 4 & 1 & Aprovado \\
\hline 4.2 . & 3 & 2 & 4 & 1 & 5 & 1 & Sem consenso & 3 & 1 & Rejeitado \\
\hline 5.1. & 3 & 2 & 4 & 1 & 5 & 1 & Sem consenso & 3 & 2 & Rejeitado \\
\hline 6.1. & 3 & 2 & 4 & 1 & 5 & 1 & Sem consenso & 3 & 0,75 & Rejeitado \\
\hline 7.1. & 3 & 2 & 4 & 1 & 5 & 1 & Sem consenso & 3 & 1 & Rejeitado \\
\hline 7.2 . & 3 & 2 & 4 & 1 & 5 & 1 & Sem consenso & 3 & 1 & Rejeitado \\
\hline 8.1. & 3 & 2 & 4 & 1 & 5 & 1 & Sem consenso & 3 & 1 & Rejeitado \\
\hline 9.1. & 3 & 2 & 4 & 1 & 5 & 1 & Sem consenso & 3 & 1 & Rejeitado \\
\hline 9.2. & 3 & 2 & 4 & 1 & 5 & 1 & Sem consenso & 3 & 1 & Rejeitado \\
\hline 9.3. & 3 & 2 & 4 & 1 & 5 & 1 & Sem consenso & 3 & 1 & Rejeitado \\
\hline 10.1 & 3 & 2 & 4 & 1 & 4 & 0 & Sem consenso & 3 & 1 & Rejeitado \\
\hline 11.1. & 3 & 3 & 4 & 1 & 5 & 1 & Sem consenso & 3 & 1 & Rejeitado \\
\hline
\end{tabular}


Indicadores finais aprovados nos dois cenários para qualificação do registro e notificação de situações de violência intrafamiliar e de exploração sexual.

CENÁRIO 1 - Indicadores com mediana $\geq 4$ e $\mathrm{d}_{\mathrm{q}} \leq 1$

1. Existência de instrumento padronizado de notificação/comunicação de violência intrafamiliar contra crianças e adolescentes nas secretarias municipais

2. Existência de equipe capacitada na Secretaria Municipal de Saúde para sistematização e análise dos dados existentes nas fichas de notificação compulsória de maus-tratos contra crianças e adolescentes

3. Número de denúncias de exploração sexual contra crianças e adolescentes realizadas através de sistema de denúncia telefônica

CENÁRIO 2 - Indicadores com Medianas $\geq 3$ e $\mathrm{d}_{\mathrm{q}} \leq 1$

1. Número de notificações/comunicações de violência intrafamiliar contra crianças e adolescentes realizadas aos Conselhos Tutelares

2. Percentual de notificações de violência intrafamiliar contra crianças e adolescentes realizadas por profissionais de saúde aos Conselhos Tutelares

3. Percentual de notificações de exploração sexual realizadas por profissionais de saúde aos Conselhos Tutelares

4. Existência de instrumento padronizado de notificação/comunicação de violência intrafamiliar contra crianças e adolescentes nas secretarias municipais

5. Existência de equipe capacitada na Secretaria Municipal de Saúde para sistematização e análise dos dados existentes nas fichas de notificação compulsória de maus-tratos contra crianças e adolescentes

6. Existência de infraestrutura (recursos materiais) para sistematização e análise dos dados existentes nas fichas de notificação compulsória de maus-tratos contra crianças e adolescentes

7. Existência de normatização de fluxo para as fichas de notificação compulsória de maus-tratos contra crianças e adolescentes preenchidas pelos profissionais das unidades municipais de saúde

8. Existência de rotinas de retorno da informação sobre as notificações de violência intrafamiliar e exploração sexual às unidades que realizam atenção às crianças e adolescentes

9. Existência de sistema articulado e informatizado de informação sobre notificações/comunicações de exploração sexual realizadas entre Conselhos Tutelares, delegacias, delegacias especializadas, Disquesdenúncia nacional, estadual e municipal

10. Número de denúncias de exploração sexual contra crianças e adolescentes realizadas através de sistema de denúncia telefônica
11. Existência de banco de dados provenientes dos serviços telefônicos de atendimento às denúncias de violências contra crianças e adolescentes

12. Existência de capacitações nos setores da saúde, educação, assistência social, guarda municipal e Conselhos Tutelares que incluam a identificação, notificação e registro das situações de violência contra crianças e adolescentes

13. Existência de equipe capacitada nos Conselhos Tutelares para sistematização e análise das notificações/comunicações de violência contra criança e adolescente

14. Existência de infraestrutura (recursos) nos Conselhos Tutelares para sistematização e análise das notificações/comunicações de violência contra criança e adolescente

15. Existência de estatísticas atualizadas (semestralmente) pelo setor saúde sobre exploração sexual contra crianças e adolescentes

16. Percentual de Conselhos Tutelares que produzem estatísticas mensais de seu atendimento a situações de violência intrafamiliar e exploração sexual contra crianças e adolescentes

17. Percentual de Conselhos Tutelares que estão cadastrados no Sistema de Informação para a Infância e Adolescência (SIPIA) e alimentam regularmente esta base de dados

18. Percentual de Conselhos Tutelares que enviam estatísticas mensais de atendimento aos Centros de Referência de Assistência Social (CRAS) e ao Conselho Municipal de Direitos da Criança e Adolescente (CMDCA) 19. Existência da variável raça/cor nos instrumentos de notificação/ comunicação de violência intrafamiliar e de exploração sexual adotados pelas secretarias municipais (segundo padrão Instituto Brasileiro de Geografia e Estatística)

20. Percentual de fichas de notificação de maus-tratos contra crianças e adolescentes adequadamente preenchidas pelos profissionais de saúde da rede municipal (preenchidas em todos os campos) adolescentes. Processos participativos permitem interação interdisciplinar e intersetorial, propiciando soluções criativas e ajustadas a cada realidade. Por outro lado, sua principal limitação é justamente refletir o patamar da consciência social de seus representantes. Em outros termos, o consenso produzido nesta proposta de criação de ferramentas avaliativas incorporou o que os indivíduos consideraram exequível e relevante a partir de suas referências profissionais e mes- mo culturais. O consenso delimita uma proposta baseada no acordo possível e não em evidências técnicas ou científicas.

Analisando-se o Cenário 1 pode-se perceber que apenas três indicadores angariaram um consenso mais forte. A maioria dos indicadores obteve escores altos em relação à relevância $\left(M_{d}\right.$ em torno de 5), à clareza $\left(M_{d}=4\right)$ e escores médios quanto à facilidade de obtenção dos dados $\left(M_{d}=3\right)$. Há uma considerável descrença na prá- 
tica de registro e disponibilidade de dados das atividades cotidianas realizadas pelas secretarias de governo.

Os três indicadores deste primeiro cenário afirmam patamares básicos e merecem atenção. O primeiro apresenta a necessidade de todas as secretarias de governo possuírem um instrumento padronizado para a notificação de situações de violência intrafamiliar. Sabe-se que isto ainda não é uma realidade, nem mesmo nas áreas de Assistência Social e Educação. O segundo indicador tanto reafirma a liderança da área da Saúde para a análise dos registros gerados, quanto pontua a necessidade de equipes devidamente capacitadas para esta finalidade. O tema da exploração sexual foi timidamente acolhido no primeiro rol dos indicadores. Somente o número de denúncias telefônicas obteve consenso em torno da facilidade de acesso deste tipo de informação, em parte devido à existência do Disque 100, revelando as dificuldades de se tratar do tema 27.

A criação do Cenário 2, incluindo os indicadores que obtiveram escores médios $\left(M_{d}=3\right)$ no quesito facilidade de acesso aos dados, permite margem de escolha mais ampliada e pode constituir ferramenta estratégica para a composição de análises avaliativas.

Resumo

A informação é essencial para o enfrentamento da violência contra crianças e adolescentes e a restauração de seus direitos. Este estudo apresenta indicadores para avaliação de ações municipais para a notificação e o registro de casos de violência intrafamiliar e exploração sexual de crianças e adolescentes formulados a partir de metodologias participativas e de consenso: Técnica Grupo Nominal (TGN) e Método Delphi. O marco referencial foi o acervo de políticas nacionais voltadas para a temática. Participaram do estudo, especialistas das cinco macrorregiões brasileiras. Foram obtidos a partir da análise de consenso dois cenários de análise incluindo, respectivamente, 3 e 20 indicadores.

Violência Doméstica; Notificação de Abuso; Violência; Indicadores
Por fim, vale refletir que para que a notificação cumpra seus objetivos informacionais e seja base para o planejamento de intervenções são necessárias ações intrasetoriais e intersetoriais que demandem e promovam fluxos contínuos de dados, em especial com os órgãos que compõem o Sistema de Garantia de Direitos. O Conselho Tutelar tem função primordial na gestão destas informações. Contudo, este órgão ainda enfrenta muitas dificuldades decorrentes da falta de recursos para sistematização dos registros, por carência de estrutura física e de profissionais capacitados, assim como pela cultura de pouca valorização da informação. Instrumento fundamental nesta missão é o SIPIA (Sistema de Informação para a Infância e Adolescência) que ainda hoje se encontra incipientemente implantado 30 .

O investimento nas distintas secretarias governamentais para a criação de instrumentos de notificação, tratamento e análise dos dados, capacitação dos profissionais, consolidação de rotinas de divulgação de informações é a grande tarefa que se impõe como urgente e inadiável.

\section{Colaboradores}

S. Deslandes contribuiu com a análise dos dados e redação do artigo. C. H. F. Mendes, J. S. Lima e D. S. Campos participaram da coleta e análise dos dados, bem como na redação do artigo.

\section{Agradecimentos}

Ao Fundo das Nações Unidas para a Infância (UNICEF) e ao Conselho Nacional de Desenvolvimento Científico e Tecnológico (CNPq). 


\section{Referências}

1. Krug EG, Dahlberg LL, Mercy JA, Zwi AB, Lozano R, editores. Relatório mundial sobre violência e saúde. Genebra: Organização Mundial da Saúde; 2002.

2. Bezerra SC. Estatuto da Criança e do Adolescente: marco da proteção integral. In: Lima CA, organizador. Violência faz mal a saúde. Brasília: Ministério da Saúde; 2005. p. 17-22.

3. Departamento de Ações Programáticas e Estratégicas, Secretaria de Atenção a Saúde, Ministério da Saúde. Linha de cuidado para a atenção integral à saúde de crianças adolescentes e suas famílias em situação de violências: orientação para gestores e profissionais de saúde. Brasília: Ministério da Saúde; 2010.

4. Leal MLP. A exploração sexual comercial de meninos, meninas e adolescentes na América Latina e Caribe. 2a Ed. Brasília: Centro de Referência, Estudos e Ações sobre Crianças e Adolescentes/ Instituto Interamericano del Niño/Ministério da Justiça/Fundo das Nações Unidas para a Infância/ Coordenadoria Ecumênica de Serviço; 1999. (Relatório Final).

5. Morais NA, Cerqueira-Santos E, Moura A, Vaz M, Koller S. Exploração sexual comercial de crianças e adolescentes: um estudo com caminhoneiros brasileiros. Psicol Teor Pesqui 2007; 23:263-72.

6. Secretaria Especial de Direitos Humanos/Ministério da Justiça. Estatuto da Criança e do Adolescente. Brasília: Secretaria Especial de Direitos Humanos/Ministério da Justiça; 2004.

7. Ministério da Saúde. Portaria GM/MS nº 1.968 de 25/10/2001. Diário Oficial da União 2001; 25 out.

8. Ministério da Saúde. Portaria GM/MS nº. 737 de 16 /05/2001. Diário Oficial da União 2001; 16 mai.

9. Ministério da Saúde. Temático prevenção de violência e cultura de paz III. Brasília: Ministério da Saúde/Organização Pan-Americana da Saúde; 2008.

10. Departamento de Análise de Situação de Saúde, Secretaria de Vigilância em Saúde, Ministério da Saúde. VIVA: vigilância de violências e acidentes, 2006 e 2007. Brasília: Ministério da Saúde; 2009.

11. Assis SG, Deslandes SF, Minayo MCS, Santos NC. Definição de objetivos e construção de indicadores visando a triangulação. In: Minayo MCS, Assis SG, Souza ER, organizadores. Avaliação por triangulação de método. Rio de Janeiro: Editora Fiocruz; 2005. p. 105-32.

12. Brasil. Parâmetros para criação e funcionamento dos conselhos tutelares (Conselho Nacional dos Direitos da Criança e Adolescente - Resolução nº. 75, de 22 de outubro de 2001). Diário Oficial da União 2001; 22 out.

13. Ministério da Justiça/Conselho Nacional dos Direitos da Criança e do Adolescente. Plano Nacional de Enfrentamento da Violência Sexual Infanto-Juvenil. Brasília: Ministério da Justiça/Conselho Nacional dos Direitos da Criança e do Adolescente; 2002.

14. Brasil. Decreto Presidencial no ${ }^{\circ} .5948$, de 26 de outubro de 2006). Diário Oficial da União 2006; 26 out.

15. Niremberg O, Brawerman J, Ruiz V. Evaluar para la transformación. Innovaciones en la evaluación de programas y projectos sociales. Buenos Aires: Paidós; 2005.
16. Jones J, Hunter D. Usando o Delfos e a técnica do grupo nominal na pesquisa em serviços de saúde. In: Pope C, Mays N, organizadores. Pesquisa qualitativa na atenção à saúde. Porto Alegre: Editora Artmed; 2005. p. 51-60.

17. Perry J, Linsley S. The use of the nominal group technique as an evaluative tool in the teaching and summative assessment of the inter-personal skills of student mental health. Nurs Educ Today 2006; 26:346-53.

18. Silva ACN, Bernardes RS, Moraes LRS, Reis JDP. Critérios adotados para seleção de indicadores de contaminação ambiental relacionados aos resíduos sólidos de serviços de saúde: uma proposta de avaliação. Cad Saúde Pública 2002; 18:1401-9.

19. Bauer M. Análise de conteúdo clássica: uma revisão. In: Bauer M, Gaskell G, organizadores Pesquisa qualitativa com texto, imagem e som: um manual prático. Petrópolis: Editora Vozes; 2002. p. 187-97.

20. Wright JTC, Spers RG. O país no futuro: aspectos metodológicos e cenários. Estud Av 2006; 20:13-28.

21. Piola SF, Viana SM, Vivas-Consuelo D. Estudo Delphi: atores sociais e tendências do sistema de saúde brasileiro. Cad Saúde Pública 2002; 18 Suppl:181-90.

22. Wright JTC, Giovinazzo RA. Delphi: uma ferramenta de apoio ao planejamento prospectivo. Caderno de Pesquisas em Administração 2000; 1:54-65.

23. Keeney S, Hasson F, McKenna H. Consulting the oracle: ten lessons from using the Delphi technique nursing research. J Adv Nurs 2006; 53:205-12.

24. Noblat L, Oliveira MGG, Santos R, Noblat ACB, Badaró R. Validation of criteria for nosocomial use of Amikacin in Brazil with the Delphi technique. Braz J Infect Dis 2006; 10:173-8.

25. Bernal-Delgado E, Peiró S, Sotoca R. Prioridad de investigación en servicios sanitarios en el Sistema Nacional de Salud. Una aproximación por consenso de expertos. Gac Sanit 2006; 20:287-94.

26. Keeney S, Hasson F, McKenna H. A critical review of the Delphi technique as a research methodology for nursing. Int J Nurs Stud 2001; 38:195-200.

27. Veras TO. Sistema Nacional de Combate ao Abuso e à Exploração Sexual Infanto-juvenil e o Plano Nacional: um exemplo de política pública aplicada. Cad EBAPE.BR [online] 2010; 8:404-21.

28. Deslandes SF, Souza ER, Minayo MCS, Krempel M, Cavalcanti ML, Lima MLC, et al. Caracterização diagnóstica dos serviços que atendem vítimas de acidentes e violências em cinco capitais brasileiras. Ciênc Saúde Coletiva 2006; 11:1279-90.

29. Njaine K, Souza ER, Minayo MCS, Assis SG. A produção da (des)informação sobre violência: análise de uma prática discriminatória. Cad Saúde Pública 1997; 13:405-14.

30. Ministério da Justiça. Manual Sipia: primeiros passos. 5a Ed. Brasília: Secretaria Especial de Direitos Humanos/Ministério da Justiça; 2001.

Recebido em 21/Dez/2010

Versão final reapresentada em 16/Mai/2011

Aprovado em 01/Jun/2011 